\title{
Develop and Implementation of Solar Powered Ventilation System
}

\author{
Hairol Nizam Mohd Shah ${ }^{1}$, Zalina Kamis ${ }^{2}$, Mohd Fairus Abdollah³ ${ }^{3}$ Mohd Khairi Mohd Zambri', \\ Faizil Wasbari ${ }^{5}$, Nursabillilah Mohd Ali ${ }^{6}$, Amirul Anwar Mat Shah \\ 1,2,3,4,6,7 Center for Robotics and Industrial Automation, Faculty of Electrical Engineering, Universiti Teknikal Malaysia \\ Melaka, Malaysia \\ ${ }^{5}$ Faculty of Mechanical Engineering, Universiti Teknikal Malaysia Melaka, Malaysia
}

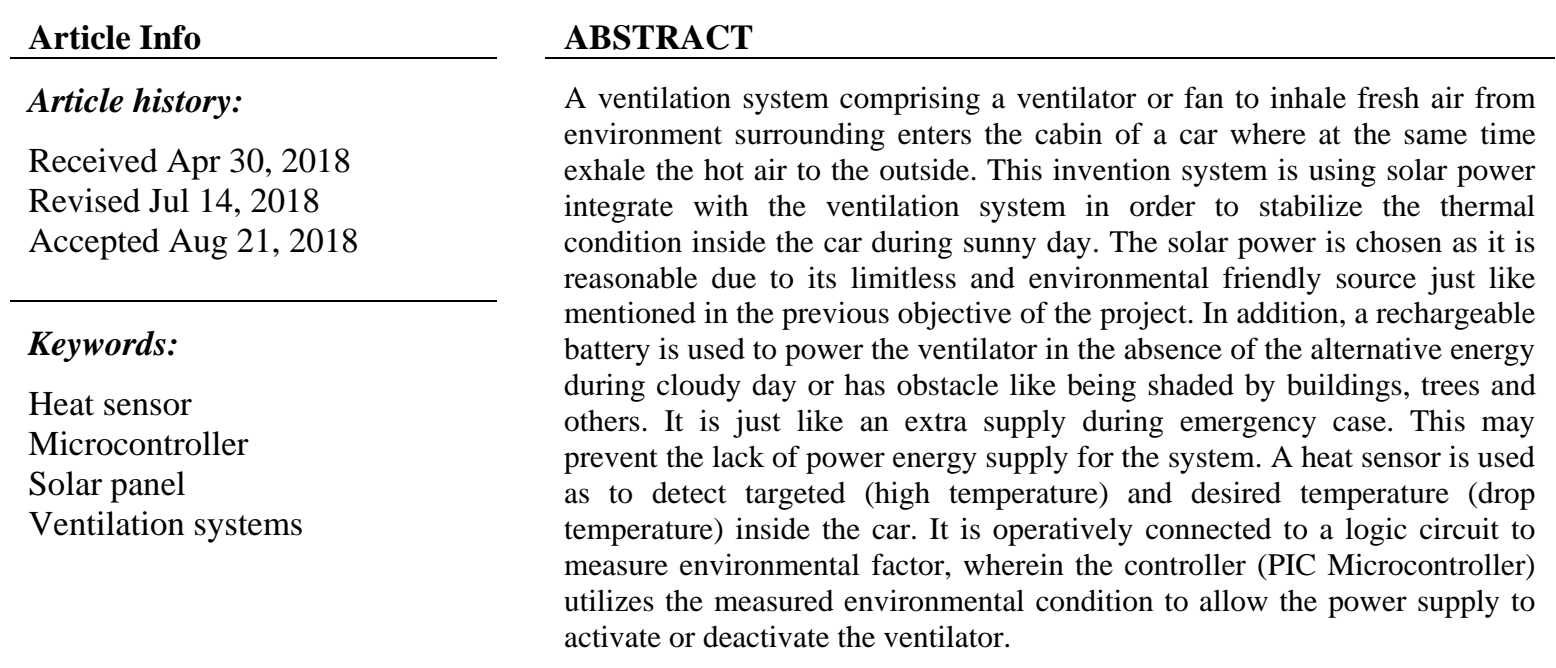

Copyright $@ 2018$ Institute of Advanced Engineering and Science. All rights reserved.

\section{Corresponding Author:}

Hairol Nizam Mohd Shah,

Center for Robotics and Industrial Automation,

Faculty of Electrical Engineering, Universiti Teknikal Malaysia Melaka, Malaysia.

Email: hnizam@utem.edu.my

\section{INTRODUCTION}

Nowadays, global warming becomes such a great issue. It gives impact in increasing the thermal condition all around the world. It is eventually warm up everything on Earth. Related to the problem statement of this project, it will heat up a car when parking at exposed area with no any shield. From here, many issues impact are appeared then. It will create an uncomfortable environment for the driver and the passengers. The fuel consumption will increase and it may give result of heat stroke. Based on the situation occurred and several impacts that have appeared, it is motivated and encouraged to create a ventilation system to stabilize the temperature inside the car. Thus, a comfort environment can be produced for user.

The problem is come up with the situation when a car is parked on the site where it is exposed directly from sunlight with no any shield. This situation usually takes place during sunny day. Thus, the heat gain inside the car will increase as the air inside the cabin of the car is warmed up as in a closed space where there is no flow in and out of air. The heat gain may reach at critical point. Most of energy source that already exists has its limit use and non-renewable. They eventually will run out as the duration to restore them is taking longer time. They also can produce pollutions. The burning fuel can emits greenhouse gases which is including carbon dioxide where can contribute in the phenomenon of global warming. 
Even solar energy is unlimited, but when having some obstacles it may affect its potential. For example, the solar panel needed to be directly exposed to sunlight in converting electricity in maximum rate. If there is cloudy day and shaded as well as shadow may decrease its ability to produce power supply. Most users prefer having something that pleasing them, not as a burden. Even the ventilation is well functioning but need to handle it manually, it will give difficulty to the user. For example, as need to handle it manually, a user may need take more time while to install it. It may affect their time if they are rushing for something.

\section{LITERATURE REVIEW}

The sun is an exhaustible source of energy [1] that is situated at the heart of the solar system. It is the most prominent feature in the solar system. It owns $99.8 \%$ of the mass of the solar system and is roughly 109 times the diameter of the Earth-about one million Earth could fit inside it. It is a fusion reactor which is burned nearly over four billion years. The Sun produces a vast amount of energy where meet the supply for world's needs in a year. In a day, it can generate a very large amount of energy than our current population would consume in 27 years.

Solar energy is a radiant light and heat that is produced by the sun. As it radiates, an enormous amount of energy is created. The solar energy has been acknowledged as a free, inexhaustible and environment friendly sources. It delivers radiation of solar energy which is received by the Earth and its atmosphere at $3.8 \times 1024 \mathrm{~J}$ per year that exceeds 8000 times our primary energy supply. This is more than enough energy to meet global demand, even allowing for the conversion, storage and transmission losses required when putting this resources to human use. Thus, it is stated that the solar energy is the principal source of energy in today's technological world [2].

Over the last few decades, solar architecture which used this solar energy has started to become popular again because conservation issues and nowadays, considerable progress has been made in promoting the solar renewable energy. Many people believed that solar energy has contributed and will continue to contribute to the national and global energy utilisation strategies [3]. Solar energy is used in various parts of industrial and commercial sectors such as agricultural, transportation, communication and others. This paper will focus more on its utility in the ventilation system of a car.

Ventilation is a no limit supply and removal of air according to a space. In simpler words, it is the intentional flow in and out of air of a space. It is applied to get rid of unpleasant smell and excessive moisture by allowing air from the outside to fill in, to maintain thermal condition of interior space. Accordance to ASHRAE Handbook [4], ventilation air is the air used to produce acceptable indoor air quality. The ventilation system is divided into three types which are natural ventilation, mechanical ventilation and hybrid ventilation.

During a car parked at exposed area where directly perpendicular towards sunlight, the thermal heat in the interior space of a car is generated will raise the interior space temperature up drastically. The thermal accumulation will cause an uncomfortable environment to the driver or the passengers during the early 10 minutes after entering a prolonged soaked car [5]. The temperature inside the car can easily rise to 60o $\mathrm{C}$ and even in fairly cloudy day, it can easily reach 55oC [6]. The equipment inside the car will absorb heat and will make the car compartment hard to be cooled down within a short period of time. In order to reduce the temperature built up during the warm up period, the drivers have to activate the air conditioner at high speed as to ensure the essential cooling process to achieve the desired temperature. The drop of in the interior temperature by running the air conditioner is higher $(50 \%)$ compared to condition where air conditioner is turned off, reflecting big influence of the air conditioning system (A/C) to obtain good thermal comfort [7]. Thus, it consequently increases the fuel consumption of the car as well as increases the emission of carbon dioxide gases. As to overcome the problem, ventilation system is created as the solution.

\subsection{Advantages of Solar Energy}

a) Environmental Friendly Source

Solar energy is known as one of ideal energy source that is renewable and non-polluting source. It does not harm the environment by emitting any hazardous or greenhouse gases such as carbon dioxide, sulfur dioxide and nitrogen oxide into the atmosphere. It also does not take part in burning any fuel and produces no emissions. Thus, this will prevent the problems of fuel consumption and the production of radioactive waste.

\section{b) Renewable and Infinite Source}

Solar energy is a renewable and totally one hundred percent free source of energy [8]. The radiation of the solar energy is long lasting and continuously as the sun remains exists. Thus, its source is never run out compared to non-renewable sources like oil, coal and natural gas. 


\section{c) Saving Eco-Systems and Livelihoods}

Because solar energy does not rely on constantly mining raw materials, it does not result in the destruction of forests and eco-systems that occurs with most fossil fuel operations [8].

\section{d) Easy Implementation}

Solar panel is easy to implement because cords, wires, or power sources are not required at all. Compared to other energy source such as geothermal or wind, they need a power station where they needed to be attached with some stuffs like drilling machines making such a difficult installation then. No new space is required as the solar panel can be placed at available location likes on the top roof.

\section{e) Maintenance is Low}

Solar cells that contained in the solar panel are able to run in a long lifetime and exactly require little maintenance only. If there is a requirement in increasing the power source, the solar cells can simply be added. Even the installation of the solar panel at first need such highly cost but it can be recovered in a long term.

\subsection{Disadvantages of Solar Energy}

\section{a) Reliability/Do Not Function at Night}

This is one of the main disadvantages because the production of solar energy is not constant. The sunlight must exist in order to generate electricity. During at night, the sun is covered by overcast skies and storms. Thus, the energy generated by the solar cells cannot be counted on at all times. This means that decentralized energy from solar cells cannot supply what the energy industry called baseline power, which supplies a constant energy need [9].

\section{b) Solar Inefficiency}

This point is another great issue that has been criticized related to the production of solar energy which comparatively inefficient. The percentage of the solar energy that could actually be captured for use as energy was relatively small, only $4 \%$ at first and later $11 \%$ [10] a number that has continued to grow with technological advances. The solar energy is in small amount that can be converted into electricity. In order to generate electricity at maximum rate, a huge surface area is demanded. However, nowadays many solutions are invented in resolving this inability and evidently it really contribute in the development of its efficiency in recent few years.

\section{c) Location}

The location of the solar panel is another consideration need to be included in one of its advantages. It plays major role in the production of electricity power supply. When area meets obstacles like cloudy day, shaded or shadow, it eventually may decrease the production rate of the electricity. Thus, more panels needed to be added to produce enough electricity.

\section{METHODOLOGY}

Heat sensor is used to sense environmental factor which is targeted and desired temperature that has been set by programming. The flow start when it detects targeted temperature which is $>340 \mathrm{C}$ inside the car, then the controller receive signal and allow power supply from solar power source or the rechargeable battery to activate the ventilators. If there is no detection on targeted temperature, then the process of activation of the fan is not launched. As the process of the ventilation takes place, the temperature will slightly decreased from time to time. When desired temperature detected at which is $\angle 30 \mathrm{oC}$, the sensor will sense it again and eventually the same process occurred where the controller will decide to deactivate the fan. The fan is still ON if no desired temperature is sensed. This flow is automatically controlled and operated continuously. Figure 1 show the flow chart presents the operation of the system. 


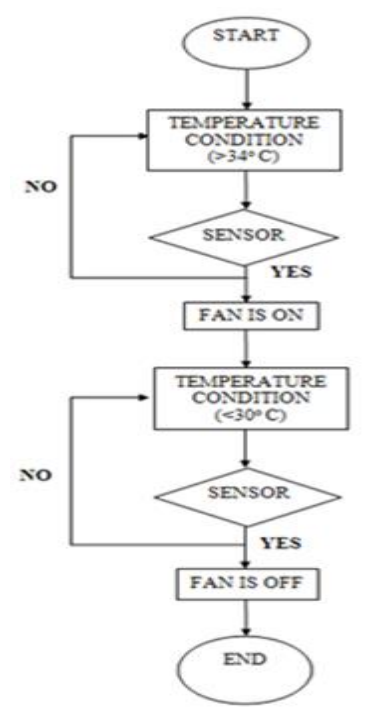

Figure 1. Flow chart the system operation

\subsection{Hardware Implementation \\ 3.1.1 Mechanical Part \\ a) Ventilators}

This project would not use any material that already been in a car. Therefore, new fan needed to be installed to function as the ventilator for the ventilation system. CPU brushless fan was preferred as the ventilator. The fan was attached into a platform of a casing which was act as the ventilator body. This casing was specially designed to create a medium where it provides a channel for the flow in and out of air can take place. The motor was placed at the centre of the inside of the casing directly near the chamber. Figure 2 show the motor fan that is used in this project. There was a gap between the fan and the chamber in order to avoid collision. The motor fan was hold securely at the platform with some screws. The specification of motor 1 and 2 is show in Table 1 and 2.

This enable the position of the motor fan can be further strengthened. The positive and negative wires from the motor's leg were twisted together as to ensure to prevent those wires from being hit by the fan. The cables then were brought out from the ventilator body via a hole that has been drilled on the casing body. Those cables were connected to the output station of temperature controller board. Two ventilators were used as to increase the efficiency of the system performance as show in Figure 3 and 4. However, both ventilators were having different direction flow of air. One was dragging air into the cabin of the car and the other one was vice versa. Thus, a cycle of flow of air was formed.

Motor fan 1:

Table 1. Specification of motor 1

\begin{tabular}{cc}
\hline Specification & Rating \\
\hline Voltage & $12 \mathrm{~V}$ \\
Current & $0.135 \mathrm{~A}$ \\
Power & $1.62 \mathrm{~W}$ \\
\hline
\end{tabular}

Table 2. Specification of motor 2

Motor fan 2:

\begin{tabular}{cc}
\hline Specification & Rating \\
\hline Voltage & $12 \mathrm{~V}$ \\
Current & $0.18 \mathrm{~A}$ \\
Power & $2.16 \mathrm{~W}$ \\
\hline
\end{tabular}




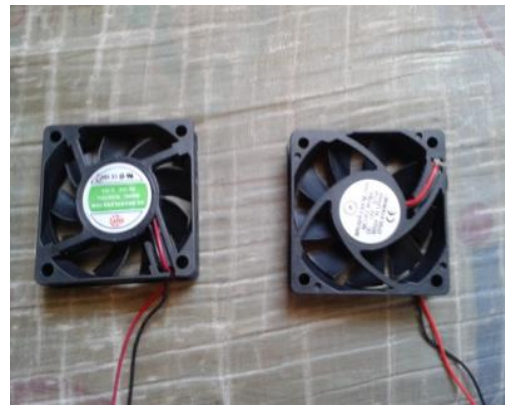

Figure 2. Motor fan

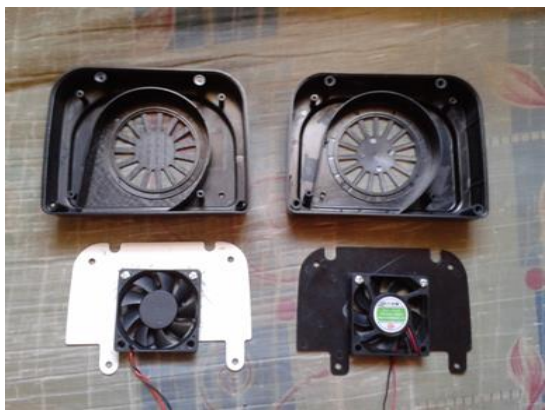

Figure 3. Motor implemented on the platform

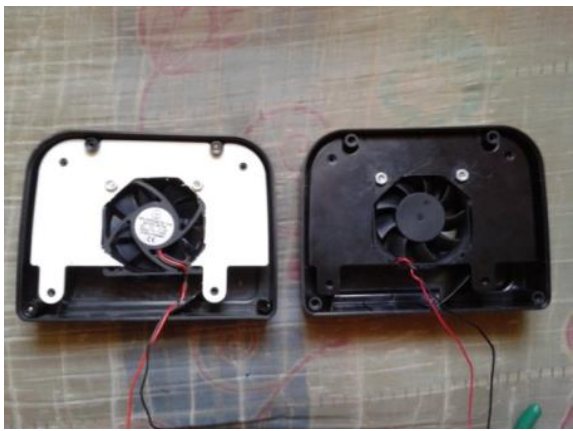

Figure 4. Ventilators (after motor fan implemented)

\subsubsection{Electrical Part}

a) Solar Panel

Solar panel was selected as the main supply energy for the system. When radiation of sunlight reaches the panel, the particles of the sunlight or called photon then converted into electrical energy. The process takes place is called photovoltaic effect. As the photon strikes on solar cell, it will trigger electron in the solar cell and cause it moving freely or in excite state. This situation will produce an electric current. The electricity power generated then used as power supply to activate the ventilator or fan.

It is a monocrystalline silicon solar panel as shown in Figure 5. Those solar cells are connected in series. It contains 36 solar cells which produce an open-circuit voltage of about $21.4 \mathrm{~V}$, as each cell can provides voltage in between $0.5 \mathrm{~V}$ to $0.6 \mathrm{~V}$. This open-circuit voltage is the voltage where there is no connection between the solar panel to any load. Hence, it produces peak amount of voltage. From this amount of voltage, it is sufficient to charge $12 \mathrm{~V}$ battery as the extra power supply for the system. Table 3 shows specification on the selected solar panel.

Table 3. Specification of monocrystalline silicon solar panel

\begin{tabular}{cc}
\hline Specification & Rating \\
\hline Rated Maximum Power & $12 \mathrm{Wp}$ \\
Maximum System Voltage & $715 \mathrm{~V}$ \\
Rated Voltage & $17.28 \mathrm{~V}$ \\
Rated Current & $0.70 \mathrm{~A}$ \\
Opened-Circuit Voltage & $21.24 \mathrm{~V}$ \\
Short-Circuit Current & $0.77 \mathrm{~A}$ \\
Test Condition & $\mathrm{AM} 1.5, \mathrm{Ec}=1000 \mathrm{~W} / \mathrm{M}^{2}, \mathrm{Tc}=25^{\circ} \mathrm{C}$ \\
Dimension & $380 \mathrm{~mm} \times 305 \mathrm{~mm}$ \\
\hline
\end{tabular}




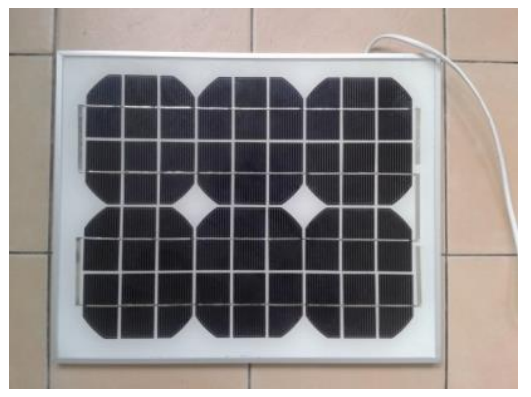

Figure 5. Monocrystalline silicon solar panel

\section{b) Installation of Ventilators}

The ventilators were designed to be placed on the top edge of both side open window of the tested car. There was air gap as the installation was done because the windows were not fully closed due to ventilator body. After taking safety consideration as prioritized, rubber strips were fitted along the top edge of the windows to fill the gap between the top edge of the window and the door frame. The strips were fitted loosely into the main unit by pushing them up into the grooves on either side of the ventilator body. Figure 6 show the top view of the position solar panel and ventilators.

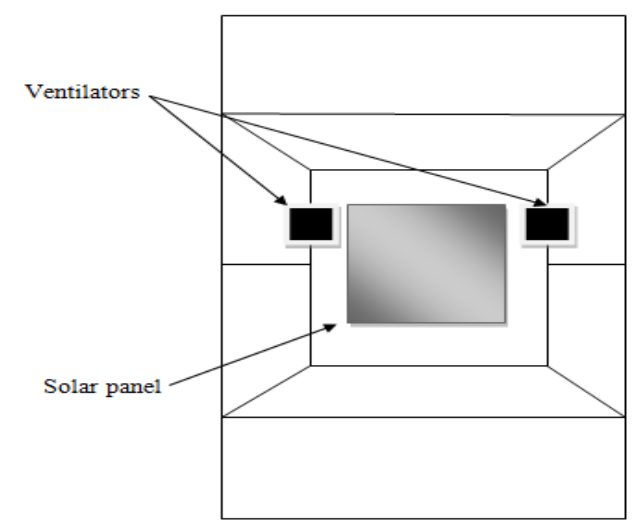

Figure 6. Top view - Position of solar panel and ventilators

The windows were kept open about several centimetres and the ventilator body was positioned on a suitable flat part of the window. Finally the strips were fitted along the top edge of the window. This can viewed in the Figure 7. The whole ventilator was placed on the top of the window. Then, the window was closed in such a way that the ventilator can be securely held in place between the window and the door frame.

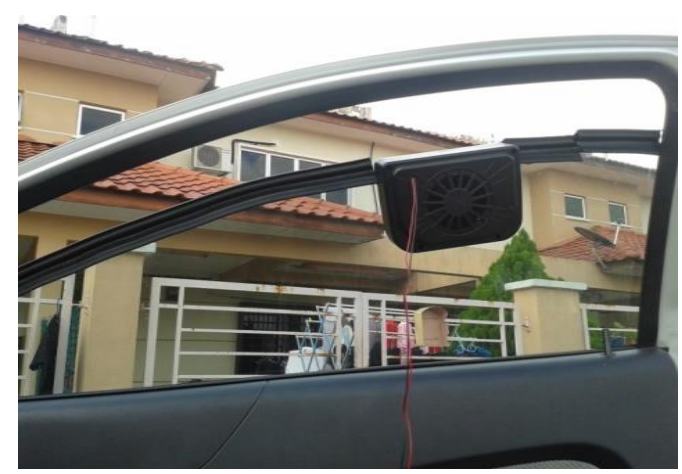

Figure 7. Location of the ventilator 


\section{c) Location of Solar Panel}

According to one of the objectives in the previous page, location of the solar panel was emphasized. It was one of the factors that should be prioritized as it affects the production of amount of power supply generated. In order the system to function effectively in smooth way, it should need enough or as much of maximum power supply as it can. Thus, the position of the solar panel is crucial to be properly placed and aligned to get most efficiency out of it. Some consideration should be included in deciding the best or suitable location for the solar panel. Here were some of the considerations that were highlighted as shown below:

\section{d) Shade and Shadow}

It is stated that intensity of radiation of sunlight affect the collection of electricity power supply produced. As the intensity is decrease, then the production of power supply is also decreased. When obstacles like shade and shadow comes up, the solar panel is blocked and no radiation of sunlight will reach it. The production of power supply is being interrupted then.

\section{e) Angle of Inclination}

Different angle of inclination will provide different amount of radiation of sunlight. To reach high intensity of sunlight, the solar panel supposedly to be directly proportional to sunlight.

[Maximum amount of sunlight $=$ angle of inclination (90o) towards sunlight]

\section{f) Movement of Sun}

The Sun appears to rise in the East and it sets in the West. Different place has different intensity of sunlight. For a country located far away from the highway of the Sun, the intensity of the sunlight is slightly low and vice versa. Luckily, Malaysia is located in the Sun belt of the Earth which is nearly to the equator. Therefore, the good thing is Malaysia having an average insolation about the same all year around.

By referred to the consideration highlighted above, with some further research and discussion, the solar panel was chosen to be placed at the top roof of the car. This position is illustrated in the Figure 8. At this position, the solar panel was able to receive directly solar irradiation in maximum amount. Hence, high production of electricity was achieved. The positive and negative wires from the solar panel were connected to the input station of the temperature controller board.

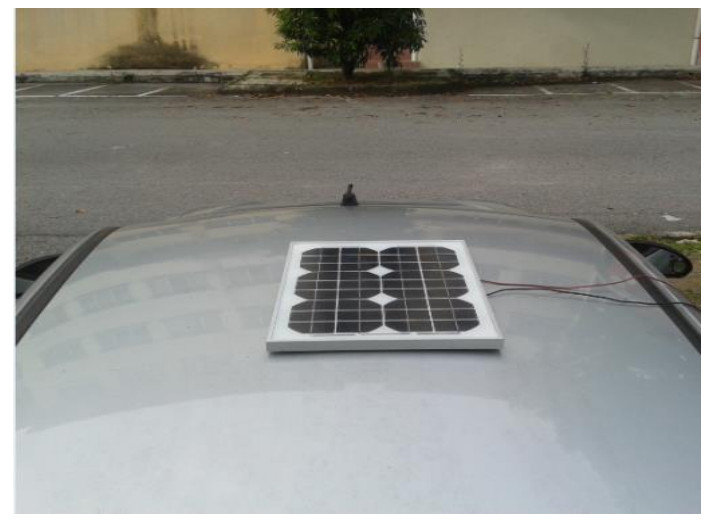

Figure 8. Top roof - position of solar panel

\subsection{Software Implementation}

\subsubsection{Microcontroller}

By using MicroC software and Proteus software, the result of the project can be illustrated. The microcontroller codes were compiled by using MicroC software. The software then installs the PIC16F876A [11] with the machines codes of the program by using PICkit 2 programmer. Then a designed circuit for the system was simulated by using Protues software which is using the PIC Microcontroller as the main controller [12-13].

However, the protues software does not provide certain component that used in actual hardware. There is a change made in order to replace the actual components to relevant components such as the input for the system. Solar panel was illustrated as a battery in the software. The progress of the simulation has been explained in the temperature controller board section. Figure 9 show the simulation circuit using Proteus. 


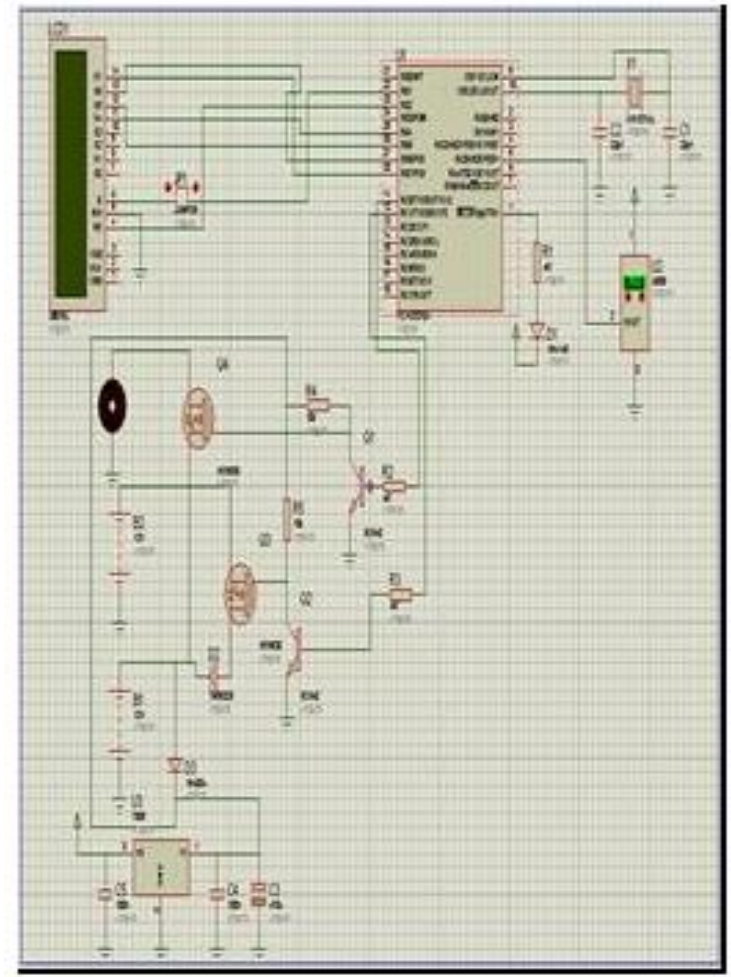

Figure 9. Simulation circuit (Proteus)

\section{RESULTS AND DISCUSSION}

\subsection{Data Collection Process}

There were several experiments or test be carried out. These tests were done in order to investigate the performance of the ventilation system. The data collections were divided into two categories:

1. Performance of ventilation system

a) Data collection without ventilator

b) Data collection with ventilator

2. Energy supply provided by the solar panel

a) Solar panel is directly exposed to sunlight

b) Solar panel is covered

A metallic grey colour Proton Satria Neo, hatchback compact car was selected as a subject test throughout the investigation. This car has dimension of overall length $=3905 \mathrm{~mm}$, overall width $=1710 \mathrm{~mm}$ and overall height $=1420 \mathrm{~mm}$. It is a clean car which is does not contain any subjective or modifications where may contribute in the interruption of the data collection, for example is tinted window. The car was parked in an open space where exposed to the sunlight in order to keep the whole ventilation system was running at its optimum level.

The solar panel, ventilators, battery and temperature controller board were installed properly. After rubber strips had been placed, the car's side windows and doors were ensured to be fully closed. For the first category test, the data acquisitions were done in sunny day from $11 \mathrm{am}-3 \mathrm{pm}$. The data were taken in every hour intervals from the data range. Due to different intensity of light between the days in Malaysia because of unexpected climate change, the data were collected in average way. The temperatures at the front dashboard and back dashboard were taken by using digital temperature indicator. At last, their average temperatures were calculated by Equation 1.

$$
\mathrm{Tf}=(\operatorname{Tmax}+\mathrm{Tmin}) / 2
$$

This test was done several times in order to obtain more accurate data measurement. For the second category test, there were two condition test were conducted. First condition, the data of supply energy were taken when solar panel is directly exposed meanwhile the second one was when the solar panel was covered. In second test, there were divided into two conditions then where the solar panel was implemented on the 
front and back dashboard. The power supply energy from the solar panel from each test was calculated by Equation 2. The performance of the ventilation system with and without ventilation is shown in Table 4- 7 while the performance energy supply provided by the solar panel is show in Table 8-10.

$\mathrm{P}=\mathrm{V} 2 / \mathrm{R}$ (Resistor used as a load)

Table 4. Average temperature (front and back dashboard) in different days

\begin{tabular}{cccccc}
\hline Time & $11 \mathrm{am}$ & $12 \mathrm{pm}$ & $1 \mathrm{pm}$ & $2 \mathrm{pm}$ & $3 \mathrm{pm}$ \\
\hline $\begin{array}{c}\text { Temperature }\left({ }^{\circ} \mathrm{C}\right) \\
\begin{array}{c}\text { Day 1 } \\
\text { Temperature }\left({ }^{\circ} \mathrm{C}\right)\end{array}\end{array}$ & 38.3 & 50.5 & 61.7 & 66.0 & 65.6 \\
Day 2 & 39.2 & 50.4 & 62.3 & 64.7 & 63.0 \\
\hline
\end{tabular}

Table 5. Average temperature

\begin{tabular}{cccccc}
\hline \multicolumn{7}{c}{ Table 5. Average temperature } & $1 \mathrm{pm}$ & $2 \mathrm{pm}$ & \\
\hline Time & $11 \mathrm{am}$ & $12 \mathrm{pm}$ & $\mathrm{pm}$ & 65.6 & 64.3 \\
\hline Average Temperature $\left({ }^{0} \mathrm{C}\right)$ & 38.8 & 50.5 & 62.0 & 65 & 6 \\
\hline
\end{tabular}

Table 6. Average temperature (front and back dashboard) in different days

\begin{tabular}{cccccc}
\hline Time & $11 \mathrm{am}$ & $12 \mathrm{pm}$ & $1 \mathrm{pm}$ & $2 \mathrm{pm}$ & $3 \mathrm{pm}$ \\
\hline $\begin{array}{c}\text { Temperature }\left({ }^{\circ} \mathrm{C}\right) \\
\begin{array}{c}\text { Day 1 } \\
\text { Temperature }\left({ }^{\circ} \mathrm{C}\right)\end{array}\end{array}$ & 41.9 & 47.1 & 52.3 & 59.4 & 56.7 \\
Day 2 & 39.7 & 45.2 & 51.8 & 56.0 & 54.3 \\
\hline
\end{tabular}

Table 7. Average temperature

\begin{tabular}{cccccc}
\hline Time & $11 \mathrm{am}$ & $12 \mathrm{pm}$ & $1 \mathrm{pm}$ & $2 \mathrm{pm}$ & $3 \mathrm{pm}$ \\
\hline $\begin{array}{c}\text { Average Temperature } \\
\left({ }^{\circ} \mathrm{C}\right)\end{array}$ & 40.8 & 46.2 & 52.1 & 57.7 & 55.5 \\
\hline
\end{tabular}

Table 8. Solar panel is directly exposed to sunlight (top roof)

\begin{tabular}{ccccc}
\hline Time & $11 \mathrm{am}$ & $12 \mathrm{pm}$ & $1 \mathrm{pm}$ & $2 \mathrm{pm}$ \\
\hline Voltage (V) & 14.43 & 16.61 & 18.27 & 17.35 \\
Power (W) & 4.43 & 5.87 & 7.10 & 6.40 \\
\hline
\end{tabular}

Table 9. Solar panel is covered (front dashboard)

\begin{tabular}{ccccc}
\hline Time & $11 \mathrm{am}$ & $12 \mathrm{pm}$ & $1 \mathrm{pm}$ & $2 \mathrm{pm}$ \\
\hline Voltage (V) & 9.04 & 13.69 & 15.85 & 14.15 \\
Power (W) & 1.74 & 4.00 & 5.35 & 4.26 \\
\hline
\end{tabular}

Table 10. Solar panel is covered (back dashboard)

\begin{tabular}{ccccc}
\hline Time & $11 \mathrm{am}$ & $12 \mathrm{pm}$ & $1 \mathrm{pm}$ & $2 \mathrm{pm}$ \\
\hline Voltage $(\mathrm{V})$ & 2.35 & 2.93 & 5.46 & 4.24 \\
Power $(\mathrm{W})$ & 0.12 & 0.18 & 0.63 & 0.38 \\
\hline
\end{tabular}

\subsection{Analysis}

Figure 10 show the average temperature versus time for with and without ventilators. There was a change in temperature flow started at $11.00 \mathrm{am}$ till $3.00 \mathrm{pm}$. The rise of temperature inside the car depends on the intensity of the radiation of the sunlight. In order to avoid lack of accuracy of the collection data, each test has been done for two days where the climate nearly similar. The temperature readings were taken averagely.

On sunny day, the temperature inside the cabin of the car started rise gradually at around 11.00 am and reached maximum at around $1.00 \mathrm{pm}$ to $2 \mathrm{pm}$, then again starts to decrease as time elapses. Referred to the graph, the highest average temperature inside the car during peak time was observed at $2.00 \mathrm{pm}$. It state that the maximum average temperature without using ventilators was $65.60 \mathrm{C}$ whereas the maximum temperature observed by using ventilators was $57.7 \mathrm{oC}$. Thus, it showed that there was a reduction between the maximum average temperatures of both tests which was about 7.90C. It means that the ventilation system 
provides about $12 \%$ reduction of temperature compared to the car without any ventilation system. Hence, the heat gain in the car was reduced after the implementation of the ventilation system.

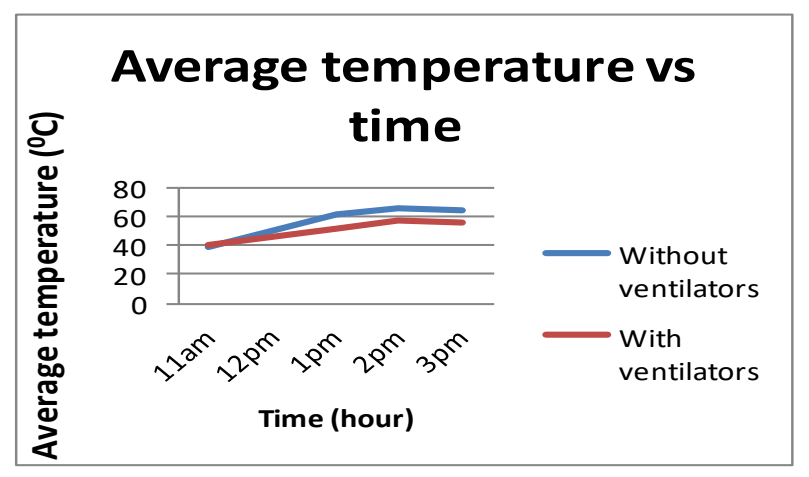

Figure 10. Average temperature versus time

Figure 11 show the power versus time for energy supply provided by the solar panel. The rating power of solar panel for each test was slightly different. This is because the position of the solar panel that has been carried in each test was implemented in different places. The maximum amount energy was produced during the tests at peak time which was at $1 \mathrm{pm}$. In test 1 , when the solar panel was placed at top roof of the car, it was directly exposed to sunlight radiation.

Hence, the solar panel can receive maximum amount of radiation of the sunlight. In these tests, a resistor, $47 \Omega$ was used as the load which is constant. The load was connected parallel with the solar panel in order to measure the voltage rating. A multimeter was used to measure the rating. Due to the Equation 2, the power measured at peak time was reached about 7.1W.

For the test of solar panel covered, there were two conditions needed to fulfill for the test to be conducted. At first condition, the solar panel was placed in the car at the front dashboard. Based on the Figure 11, it mentioned that the power produced is about $5.35 \mathrm{~W}$ at peak time. In second condition, the solar panel is positioned at the back dashboard. It showed that the solar panel was produce $0.63 \mathrm{~W}$ at the peak time.

In comparison between the supply energy from the solar panel in solar panel is directly exposed to sunlight and solar panel is covered the solar panel has potential to collect maximum amount of sunlight. It was exposed directly to sunlight in any angles without any shade or shadow. Meanwhile in solar panel covered, it cannot trap maximum amount of sunlight because it was blocked by shadow or shade by the body part of the car. In fact, the sunlight needed to penetrate the windows before it reach to the solar panel. These are some factors that affect the production of power supply energy.

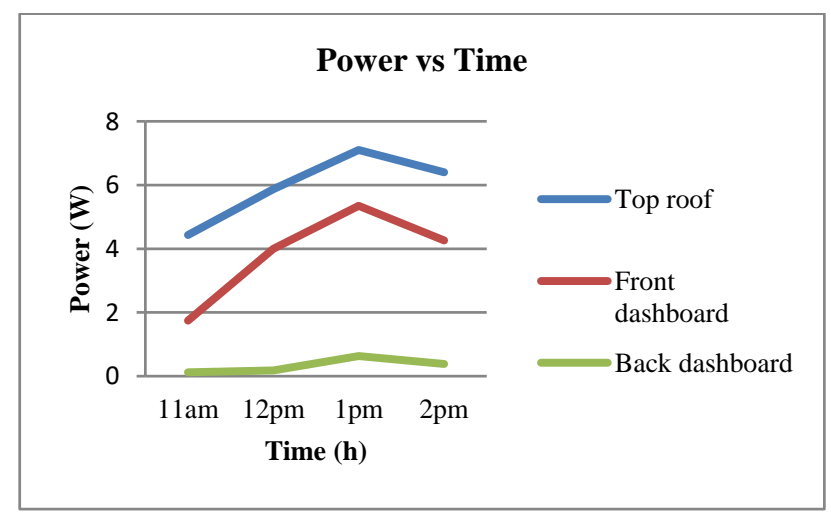

Figure 11. Power versus time 


\section{CONCLUSION}

As a conclusion, this research has successful achieved all the objectives. The ventilation system was operated by the environmental friendly source energy which is solar energy. It is one of ideal energy source that is renewable, inexhaustible and non-polluting source. The solar panel was chosen to be implemented on the top roof of the car. At this position, the solar panel was exposed directly from any angles where enable it to collect maximum energy from the sunlight. This statement was proved throughout the investigation made on the tests of energy supply provided by the solar panel that has been carried out. The position was the most effective location to be compared with other choices. Besides, the ventilation system was equipped intelligently with PIC Microcontroller which controls the system automatically. Thus, the system was function more efficiently. Based on the analysis tests of performance of the system, it showed that the heat gain inside the cabin of the car was reduced after the ventilation system was applied. It mentioned that the system provides about $12 \%$ reduction of heat temperature inside the car. Thus, it can create a comfort environment for the passengers on their initial entrance to the vehicle, keeping the interior cooler

\section{ACKNOWLEDGEMENT}

The authors are grateful for the support granted by by Center for Robotics and Industrial Automation, Universiti Teknikal Malaysia Melaka (UTeM) in conducting this research through grant PJP/2018/FKE(4C)/S01605 and Ministry of Higher Education.

\section{REFERENCES}

[1] Diane Little., "Solar energy", EFMR Monitoring Group, Inc.

[2] Porter, G., "Criteria for Solar Energy Conversion, Light Chemical Change and Life: A Source Book". in Photochemistry Wallon $2^{\text {rd }}$ Edition, Hall, Milton Keynes, 1984.

[3] Ponting, R. L., "Exploring tile Limits of Solar Power: Defining tile Boundaries and Pushing tile Envelope", Solar Energy Technology, 1992.

[4] "Ventilation and Infiltration chapter, Fundamentals volume of the ASHRAE Handbook", ASHRAE, Inc.,Atlanta, GA, 2005.

[5] M.A. Jasni and F.M. Nasir., "Experimental Comparison Study of the Passive Methods in Reducing Car Cabin Interior Temperature", International Conference on Mechanical, Automobile and Robotics Engineering (ICMAR 2012), 2012.

[6] R. Saidur, H. H. Masjuki and M. Hasanuzzaman., "Perfromance Of An Improved Solar Car Ventilator", International Journal of Mechanical and Materials Engineering (IJMME), Vol. 4(1), pp. 24 -34, 2009.

[7] Manning, R and Ewing, J., "Temperatures in Cars Survey”. RACQ Vehicles Technologies, 2009.

[8] Greg Whitburn., "13 Fundamental advantages and disadvantages of solar energy", exploring green technology, www.exploringgreentechnology.com

[9] Ethan Goffman., "Why not the sun? Advantages of and problems with solar energy", Green Match, www.greenmatch.co.uk

[10] Lund, H, R. Nilsen, O. Salomatova, D. Skåre, E. Riisem., “The History Highlight of Solar Sells [sic] (Photovoltaic Cells))". Norwegian University of Science and Technology, 2008.

[11] HNM Shah, MZ Ab Rashid, MF Abdollah, MN Kamarudin, CK Lin, Z Kamis, "Biometric voice recognition in security system", Indian Journal of Science and Technology, Vol 7(2), pp. 104-111 (2014).

[12] HNM Shah, MZA Rashid and Y.T Tam, "Develop and Implementation of Autonomous Vision Based Mobile Robot Following Human", International Journal of Advanced Science and Technology, Vol. 51, pp. 81-91 (2013).

[13] HNM Shah, MZA Rashid, NMM Sobran, RM Nor, Z Kamis, "Autonomous Mobile Robot Vision Based System: Human Detection By Color", Journal of Theoretical \& Applied Information Technology, Vol. 55(2), pp. 183-189 (2013).

[14] HNM Shah, MZA Rashid, YT Tam, "Develop and Implementation of Autonomous Vision Based Mobile Robot Following Human", International Journal of Advanced Science and Technology, Vol. 51, No 2, pp. 81-91, 2013.

[15] Hairol Nizam Mohd Shah, Marizan Sulaiman, Ahmad Zaki Shukor, Zalina Kamis, Azhan Ab Rahman, "Butt welding joints recognition and location identification by using local thresholding", Robotics and ComputerIntegrated Manufacturing, vol. 51, pp. 181-188, 2018. 